\title{
誘導式自在ボーリングを併用した急速浸透注入工法と地盤改良効果 ${ }^{+}$

石井 裕 泰* $\quad$ 小 泉 亮之助**
三 和 信 二*** 小 山 忠 雄 ${ }^{* * * *}$ \\ Study of Rapid Permeation Grouting and Its Effectiveness with Use of Horizontal Directional Drilling
}

by

\author{
Hiroyasu Ishi $^{*}$, Ryonosuke Korzumi ${ }^{* *}$, Shinji Mrwa ${ }^{* * *}$ and Tadao Orama ${ }^{* * * *}$
}

\begin{abstract}
This paper describes the field experiment of permeation grouting for soil improvement using horizontal directional drilling and chemical grouting. The rapid permeation grouting method was newly developed and subjected to the field test. Five improvement bodies were made applying different grouting processes and performance of the present method was found to be feasible. Investigations were conducted after grouting, which included the removal of overburden, direct observations of the improved bodies and laboratory tests performed on undisturbed samples. Effectiveness of improvement was found through unconfined compressive strengths and cyclic loading performance compared with the original soil.
\end{abstract}

Key words : Horizontal directional drilling, Permeant grouting, Ground improvement, Liquefaction, Packer

\section{1 は じめに}

近年，耐震指針の改訂，あるいは火災など二次災害等 に対する意識の高まりから，既存施設の耐震性能を向上 させる必要性が高まっている。特に, 施設における生産 活動を阻害することなく施工ができれば，事業者にとっ て大きなメリットになるものと考えられる，著者らは， 斜め, 曲がり, 直線削孔を可能とする自在ボーリングを 利用することにより，既設構造物直下地盤への適用が可 能な地盤改良工法を開発してきた.1)この中で，地盤を乱 すことなく間隙水を改良材で徐々に置き換える浸透注入 工法は，上記メリットを有しながら地盤の液状化抵抗を 高めることが可能で，施設の基礎部分から耐震性能を高 める手法である.

従来からの鉛直ボーリングを用いた浸透注入では, 様々な注入方式が実用化されている。しかし自在ボーリ ングで用いる管は曲線追随性を確保するため管径, 肉厚 が制約されることから，適用できる注入管にも制約があ る.このため, 注入効率の向上などを目指した注入方式 等については，既往の報告 ${ }^{2}$ の中でも積極的に検討されて きたとは言えない，そこで著者らは注入作業（通常数〜 十数時間）の効率を高めるため, 新たな注入方式の開発 を行った，本論文では，本手法を用い直径 $3.7 \mathrm{~m}$ の球状 改良体を造成した施工試験の概要, およびその地盤改良 効果について報告するものである。

\section{2 工法および施工試験の概要}

開発技術においては，1）削孔経路に沿った薬液の逸 走防止を高めるための地山パッカー (External Packer), 2) 注入効率を高めるために多数のスリットがついた注入 外管 (Flexible Casing Pipe)，3) 注入経路を簡素化するこ とで装備の小型化が図られたセルフパッカー方式の注入

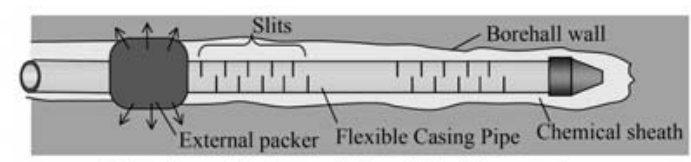

(a) Installation of Flexible Grout pipe

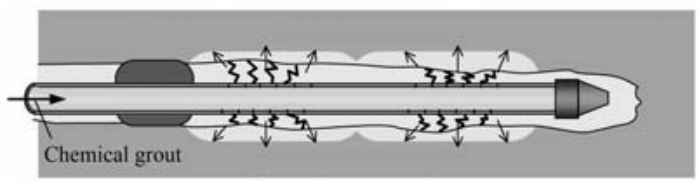

(b) Pre-grouting

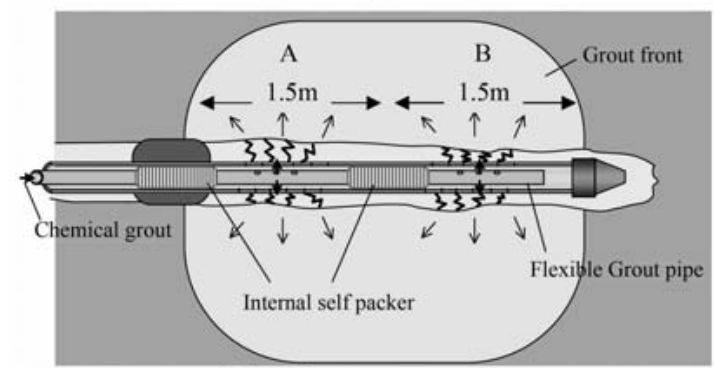

(c) Permeant grouting

Fig. 1 Process of grouting.

\footnotetext{
$\dagger$ 原稿受理 平成 19 年 3 月 27 日 Received Mar. 27, 2007 C 2008 The Society of Materials Science, Japan

* 大成建設株技術センター †245-0051 横浜市戸塚区名瀬町, TAISEI CORPORATION, Tech. Center, Totsuka-ku, Yokohama, 245-0051

** 三信建設工業(株) †112-0004 東京都文京区後楽, SANSHIN CORPORATION, Bunkyo-ku, Tokyo, 112-0004

***（株キャプティ７230-0045＼cjkstart横浜市鶴見区末広町, Capty Co., Ltd., Tsurumi-ku, Yokohama, 230-0045

**** 強化土エンジニヤリング(株) †113-0033 東京都文京区本郷, KYOKADO ENGINEERING CO., LTD, Bunkyo-ku, Tokyo, 113-0033
} 
内管 (Flexible Grout Pipe) 尚を併用することを特徴とす る (Fig. 1)。従来型に見られる等間隔に注入孔を設けた 注入外管を用いる場合に比べると, 同等の注入圧で注入 量を増やすことができ，注入時の施工効率を高めること ができる方式であると言える。曲がりボーリングにより 敷設された削孔管内にこれらを挿入し削孔管を引抜くと， 注入作業に必要な装備のみを地盤中に敷設することがで きる。な打，必要な口径を確保するために自在ボーリン グには 2 重管削孔方式を採用する.4)

施工試験は茨城県神栖市内の工場敷地内にて実施し た. Fig. 2 に実施個所付近の調查ボーリング結果, Fig. 3 に 施工計画図を示す.上部埋土層 (G.L. - 3.5m), 緩い細砂 層 (G.L. - 3.5m 〜-7.6m)，締まった砂層 (G.L. $-7.6 \mathrm{~m} \sim$ ) からなり，緩い細砂層内に地盤改良範囲（G.L.-3.5m 〜 $-6.5 \mathrm{~m}$ ，細粒分含有率 $=4 \sim 10 \%)$ を設定し注入を計画 した。な打，後述の事後調査に打いては G.L. $-3.5 \mathrm{~m}$ 以深 から部分的にコンクリートガラ等が出現し, 実際の埋土 層, 細砂層の境界は Fig. 2 に対して不陸があった可能性 が高い. 長さ $44 \mathrm{~m}$, 到達深さ $5.0 \mathrm{~m}$ の削孔を 2 本行い, 先 端部にそ机ぞれ改良体を 3 体，合計 6 体を計画した。 そ れぞれの改良体は, Table 1 に示寸条件, Table 2 に示す 順序で注入を行った。これらは, 粗詰め注入 (Pre-grouting) の有無, 浸透注入に際して一括あるいは分割で行う かにより条件設定し, 本開発手法自体の有効性とともに 1）粗詰め注入よる孔壁周辺部の安定性向上，2）隣接す

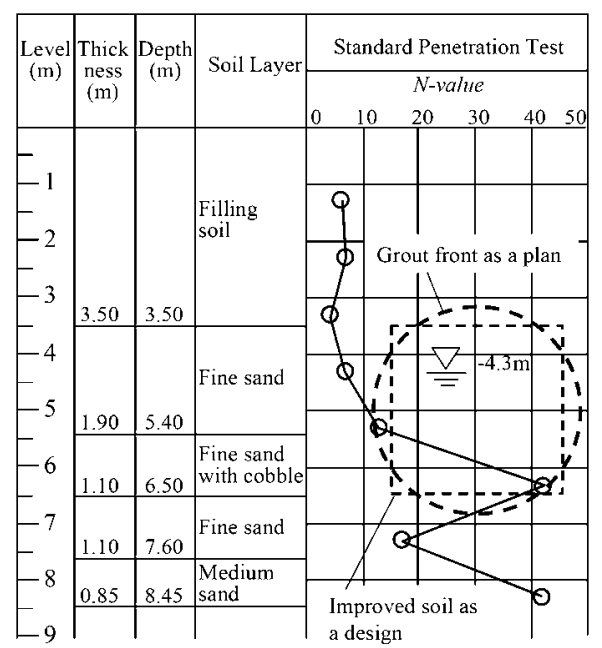

Fig. 2 Soil Profile.
る注入部分の分割施工，について検討することを目的と した。ここで, 粗詰め注入とは本注入に先立ち注入管周辺 地山を強化するための注入を言う。また，分割施工とは 一括注入 (Fig. 1 (c)でA，B 部分を同時注入) を標準的 な手法と位置付けた上で, A：発進口側を先行注入, B： 先端側を翌日に注入した場合の改良状況を確認するもの である。これは，注入作業中に打いて，本来安定すべき 吐出量, 吐出圧に変動が生じたり地表面への漏液が観察 されるなどの場合には，隣接する部分からの注入により 改善を図ることが実務上求められることを想定している. 本検討を通して，そのような手順の有効性を確認するこ とを目的とした。

削孔にあたっては電磁ロケーターにより削孔管先端部 の位置検知を行うとともに, 完了時には挿入式ジャイロ を用いて削孔線を確認した。 また、浸透注入に際しては， 「浸透固化处理工法技術マニュアル」5)に示された標準的 な吐出量 $15 \mathrm{~L} /$ 分に対して、事前の限界注入速度試験に 基づき吐出量を $20 \mathrm{~L} /$ 分とした.

なお，地山パッカー，粗詰め注入には速硬性懸濁型材 料を, 浸透注入にはコロイダルシリカをべースとしたシ リカ系材料の恒久グラウトを使用した。

\section{3 施工試験 結 果}

Fig. 4 に, 吐出量, 吐出圧の経時変化を示す。ここで は，標準手法として No.2-3 と同条件で実施した No.2-1 の結果，打よび打打むね同様の結果を得たNo.1-2 の結果 は記載を省略している.

地山パッカーおよび粗詰め注入後に平行して注入した No.1-3，2-2 では，地表面に漏液が発生したため，分割 注入の発進口側, 先端側とも吐出量を $10 \mathrm{~L} / \mathrm{min}$ （限界吐 出量の半分）で吐出圧を制御した. No.1-3，2-2 とも, (A) 発進口側の注入開始直後に高い吐出圧 $(3 \mathrm{MPa}$ 程 度）となっているが，注入管内に残されていた微細な固

Table 1 Test Cases.

\begin{tabular}{c|l|l|l}
\hline $\begin{array}{c}\text { Improvement } \\
\text { body No. }\end{array}$ & Pre-grouting & \multicolumn{1}{|c|}{$\begin{array}{c}\text { Permeant } \\
\text { grouting }\end{array}$} & Remark \\
\hline $1-1$ & Not included in present study & \\
\hline $1-2$ & Done & Full & \\
\hline $1-3$ & Not done & Separated & \\
\hline $2-1$ & Not done & Full & Basic Case \\
\hline $2-2$ & Done & Separated & \\
\hline $2-3$ & Not done & Full & Basic Case \\
\hline
\end{tabular}

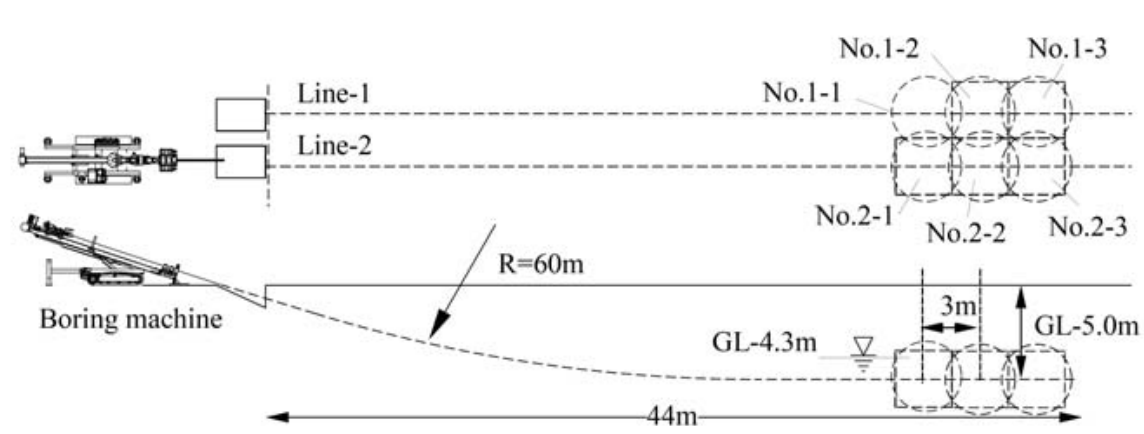

Fig. 3 Test Plan.
Table 2 Procedure of Test.

\begin{tabular}{c|c|c}
\hline $\begin{array}{c}\text { Test } \\
\text { Step }\end{array}$ & No. & Type of grouting \\
\hline 1 & All & External packer \\
\hline 2 & $1-2$ & Pre-grouting \\
& $2-2$ & \\
\hline 3 & $1-3$ & Permeant grouting: \\
& $2-2$ & Part A \\
\cline { 3 - 3 } 4 & & Part B \\
\hline 5 & $2-3$ & Part A\& B \\
\hline 6 & $1-2$ & Part A \& B \\
\hline 7 & $2-1$ & Part A \& B \\
\hline
\end{tabular}



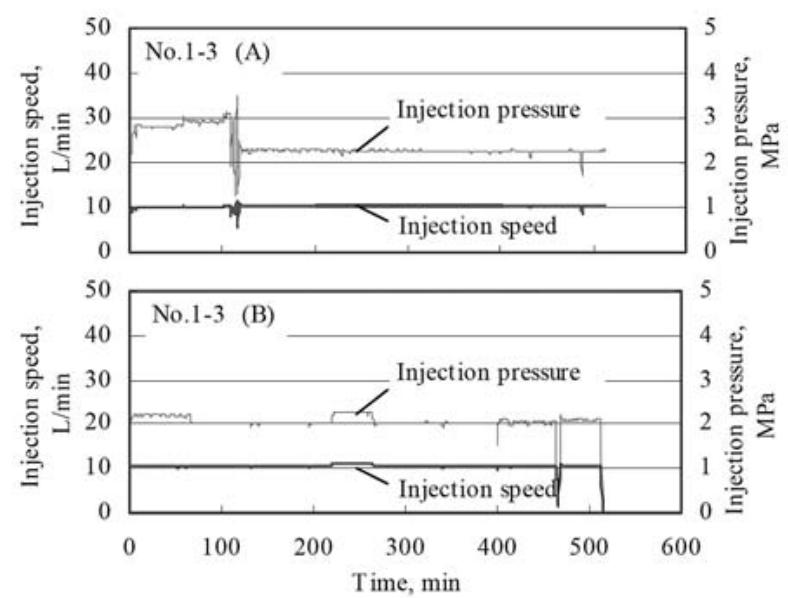

(a) No.1-3 (separated injection without pre-grouting)
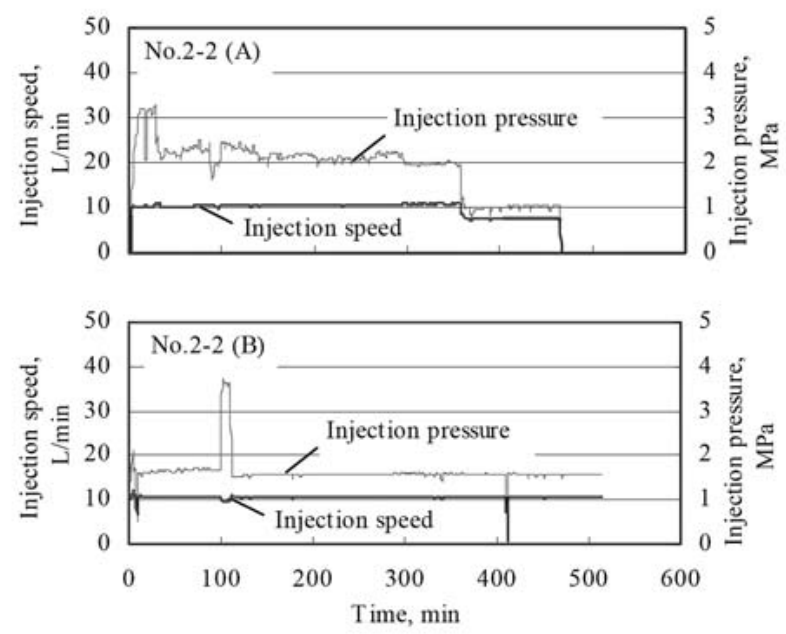

(b) No.2-2 (separated injection with pre-grouting)

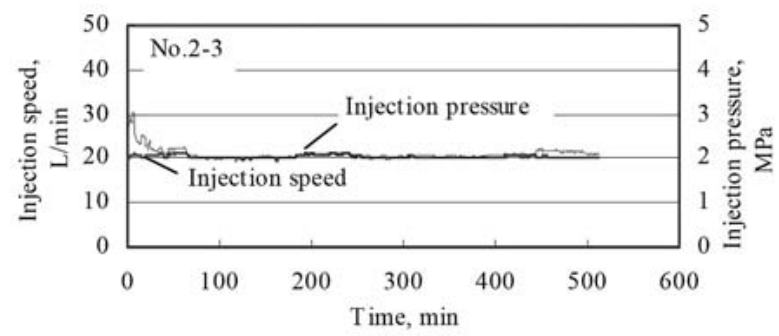

(c) No.2-3 (full injection without pre-grouting)

Fig. 4 Record of injection speed and injection pressure.

形物等が影響したものと思われ，以降同じ管を転用した 作業では見られなかった。 No.1-3，2-2 の吐出圧はとも に, 部分的には変動が見られたものの $1.6 \sim 2 \mathrm{MPa}$ 程度 で安定して注入が行われた. No.2-2 (A) 発進口側 360 分 ほどで吐出圧，吐出量が減少しているが，地上への漏液 が新たに見られたため吐出圧を $1 \mathrm{MPa}$ に落として施工を 行ったためである。引き続き一括注入の条件で施工した No.2-3, No.1-2 では, 当初計画の吐出量 $20 \mathrm{~L} / \mathrm{min}$ を吐 出圧 $2 \mathrm{MPa}$ 程度で終始安定した注入が行われた。

Fig. 5 , Fig. 6 に，施工後 1 ヶ月ほど後に地盤を掘削 し，改良状況を確認した状況を示す。ここで，掘削は注 入管の深度 (G.L. $-5.0 \mathrm{~m})$ まで行い目視確認, ブロックサ

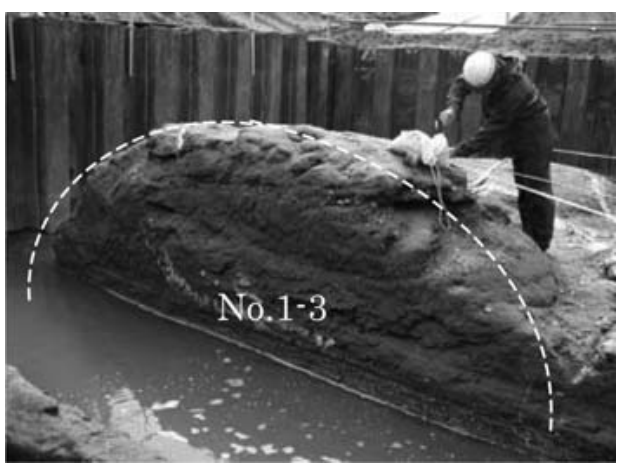

Fig. 5 Observational section of No. 1-3.

ンプリングを行うと同時に, 格子状にボーリング調查を 行い改良範囲下部の注入範囲を調べた。改良範囲上面が 計画高さに達していないのは, ロングゲルタイム（今回 の計画注入時間約 9 時間にあわせて薬液を配合）に調整 した薬液が, 結果的に地下水位付近まで沈降したためと 推測される。このため，地下水位から注入管の深度にか けては，浸透が横方向に計画範囲より広がっている。ま た，A 線に沿った改良体 No.1-2，1-3 の下部（Section 2, 4 の A下部) の浸透深さが計画より浅くなっている. 双 方の施工条件は粗詰め注入の有無，一括・分割注入とも 異なる条件であり，注入手法とは別の地盤の不均一性等 が原因になったものと考えられる。 その他については，改 良体下部でも計画範囲にわたり浸透が確認され，分割注 入を行った場合でも一括注入による注入形状とは大きな 違いは認められなかった。すなわち, 先行する注入で漏液 などが認められた場合でも引き続き隣あう地点からの注入 である程度補完できることを確認できた。

\section{4 室内試験による改良効果の確認}

ブロックサンプリングにより採取した供試体に対して 実施した材龄約 1 ヶ月での一軸圧縮試験の結果を Fig. 7 に示す。ここでは各 2 供試体の平均值を注入管からの距 離でまとめている．注入管からの距離により全体的に強 度が減少する傾向が見られるが，1m の浸透距離で $50 \%$ 程度の低减を確認した既往の研究 6)ほどではなく，200 $400 \mathrm{kPa}$ 程度の固結強度に達したことを確認した。なお， 一軸圧縮強さのうち No.1-3 の結果に着目すると距離に 応じて増加する傾向にあるが, 本研究の範囲では原因を 特定するに至ってない，また，No.1-3 周辺の地下水位付 近で採取した未改良部，No.2-3 より採取した改良部の各 不覮乱試料に対して繰返し非排水三軸試験を実施した。 Fig. 8 に示すように，改良体においては未改良の場合に 生じるような軸ひずみの蓄積は見られず，繰返し載荷に 対する安定性が向上したことを確認できた。

\section{5 ま と め}

本試験施工を通し、注入工程の効率化を目指した新た な注入方式についてその有効性を確認した。

今後も, 既設構造物直下の地盤改良に適用可能な工法 として, 誘導式自在ボーリング, 注入改良を融合した本 工法についての研究・開発を進めていきたい. 


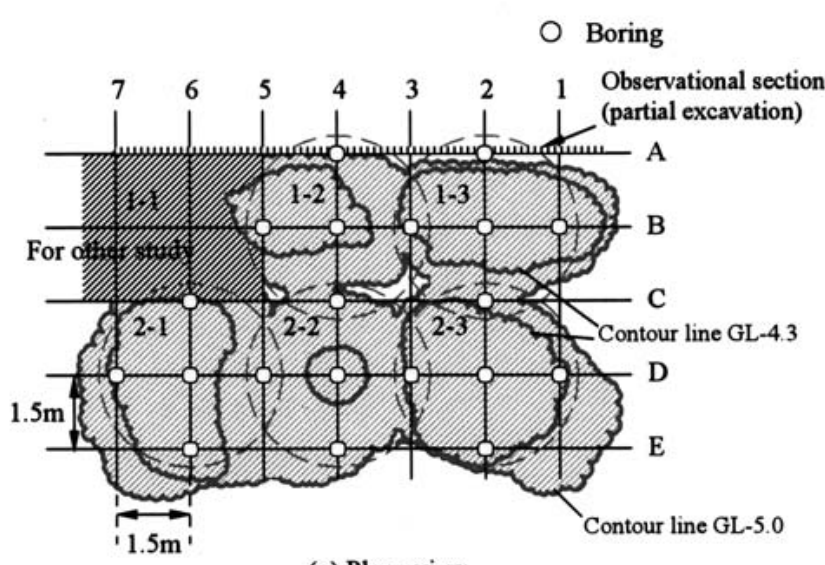

(a) Plane view

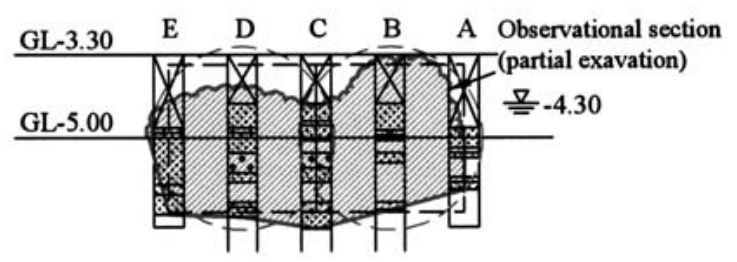

(b) Section-2

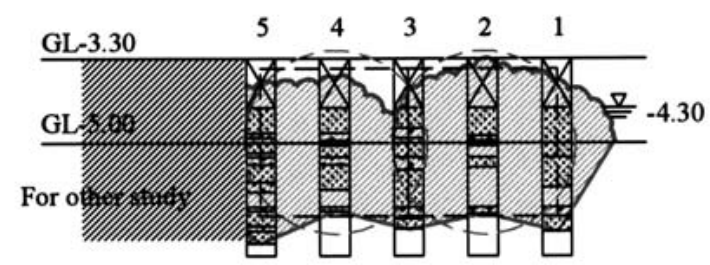

(c) Section-B

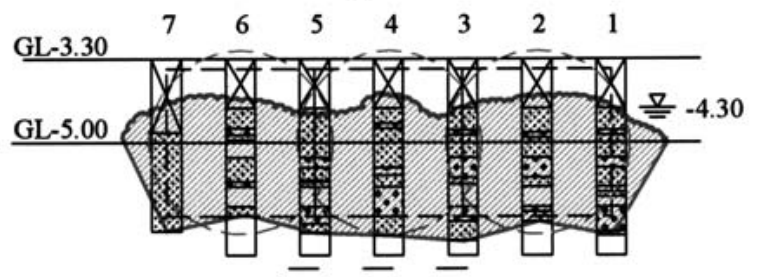

(d) Section-D

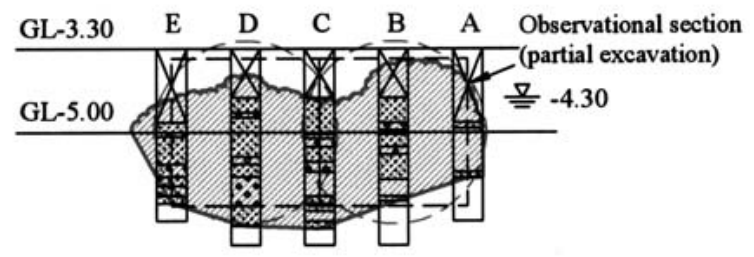

(e) Section-4

Fig. 6 Observation of grout front.

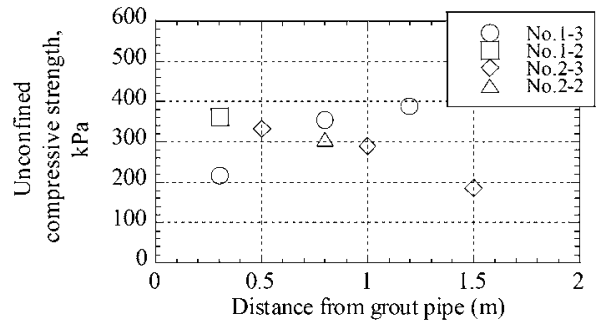

Fig. 7 Distribution of unconfined compressive strength.

\section{参 考 文 献}

1) H. Ishii and K. Higaki, "Development of ground-improvement method under existing structures”, Electric Power Civil Engineering, Japan, No.326, pp.70-73 (2006).

2 ) H. Yamazaki, M. Mukai, T. Yamada, T. Mihara and J. Yokoo, "Field experiment of liquefaction countermeasure by chemical grouting using horizontal directional drilling", Journal of Japanese Society of Civil Engineering, No.756/VI62, pp.89-99 (2004).

3 ) S. Shimada, S. Kawai, T. Suzuki and R. Koizumi, "Development of chemical grouting method beneath exisiting structures", $60^{\text {th }}$ Annual Conference of Japanese Society of Civil Engineering, 6-256 (2005).

4) H. Ishii, R. Koizumi, S. Miwa and T. Oyama, "Study of rapid permeation grouting and its effectiveness with use of horizontal directional drilling”, Proceedings of the Seventh National Symposium on Ground Improvement, pp.77-80 (2006).

5 ) “Shintou koka shori kouhou gijutu manual”, Coastl Development Institute of Technology, p.43 (2003).

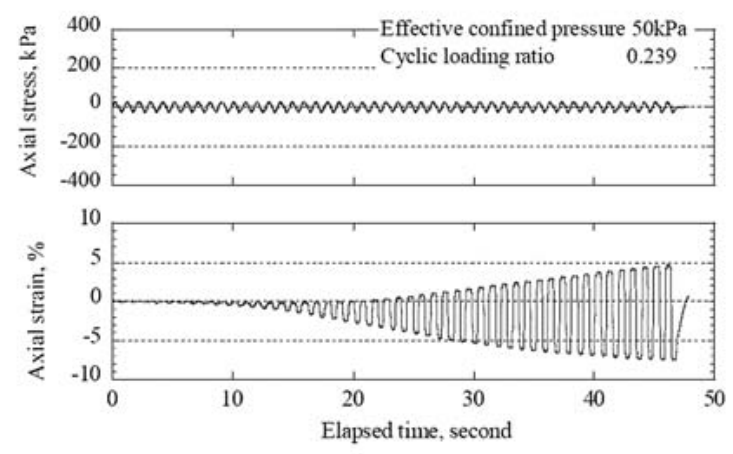

(a) Original soil
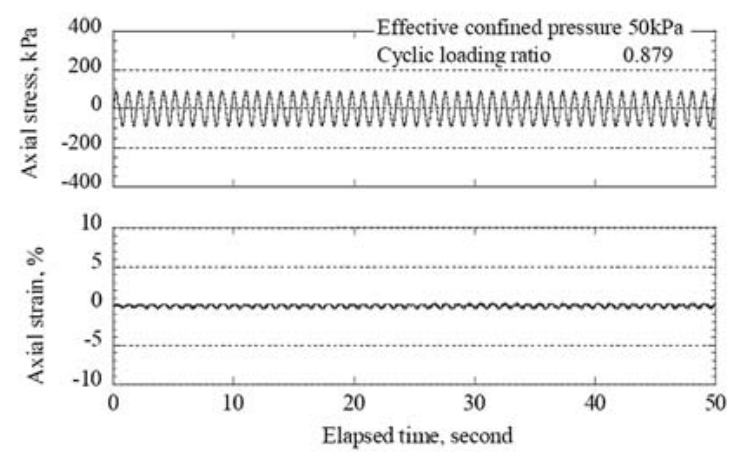

(b) Improved soil with grouting

Fig. 8 Undrained triaxial cyclic loading tests.

6) K. Hayashi, K. Zen, H. Yamazaki and N. Hayashi, "A large soil stratum test on the permeability and the improved strength of new solution type chemical grout”, Journal of Japanese Society of Civil Engineering, Japan, No.694/III-57, pp.221-228 (2001). 